\title{
MEDIATING EFFECT OF HRM PRACTICES ON LEAN MANAGEMENT AND OPERATIONAL PERFORMANCE: A CONCEPTUAL FRAMEWORK
}

\author{
Azhani Ismail \\ Faculty of Industrial Management, University Malaysia Pahang; azhani2013@gmail.com \\ Yuserrie Zainuddin \\ Faculty of Industrial Management, University Malaysia Pahang; yuserrie@ump.edu.my
}

\begin{abstract}
Public sectors in Malaysia are operating in a rapidly-changing world. The emergence of globalization, the borderless world and increasing budgetary constraints are major challenges to the public sectors in ensuring continuous improvement in service delivery to customers. This paper presents a conceptual framework with the major objective to investigate from the resource-based view theory perspective, the mediating effect of human resource management practices on the relationship between lean management and operational performance within Malaysia public sector. The main research question addresses by this study is whether lean management enhances operational performance directly or indirectly through the support of the human resource management practices. The conceptual model could build momentum by stimulating new research in public sector which is anticipated to be a framework for future studies in the academic field and public sector lean management implementers.
\end{abstract}

Keywords: lean management, human resource management practices, operational performance, public sector

\section{Introduction}

The concept of operational performance (OP) is a topic under much discussion today. It is considered as a path to being the best-in-class performer since improving operations can be an effective way to improve the overall performance of an organization. OP is an important contribution which is about adopting approach to strengthen processes in an organization to stimulate growth and improvements in productivity. The future of the organization lies in the degree of efficiency and continuous commitment to manage the key resources effectively that would be strengthened by the ability to continuously upgrade the level of efficiency and management skill (Hamid, Hamali and Abdullah, 2016).

This research look into the performance of organization in the public sectors, particularly in the local government in Malaysia. For Malaysia to achieve its 2020 goal of becoming an advanced economy and inclusive nation, it is vital to set the country on an accelerated growth trajectory (EPU, 2017). The current fiscal environment, globalization, the borderless world and ongoing demographic challenges make the task of improving public sector OP even more pressing (MPC, 2017).

Over the years, many researchers have demonstrated that investments in human capital can significantly influence organizational objectives and outcomes (Hatch and Dyer; 2004, Marshall, 2014). The resource-based view (RBV) theory perspective has been extensively utilized to empirically test and predict these organizational objectives and outcomes, such as increased productivity (Huselid, 1995; Black and Lynch, 1996), manufacturing performance (Challis, Samson and Lawson, 2005), operational performance (Ahmad and Schroeder, 2003; Dan and Yuxin, 2011), organizational performance (Becker and Gerhart, 1996; Delaney and Huselid, 1996), and individual performance (Myers, Griffith, Daugherty and Lusch, 2004).

From strategic management and organizational economics, the RBV is found appropriate, presenting the role internal resources play in developing and sustaining an organization's competitive advantage and performance (Barney, 1991; Wright and McMahan, 1992; Wright, McMahan and McWilliams, 1994). A variety of definitions have been offered when refer to these internal resources (Fok-Yew, 2016). However, the argument established in this study is focus on managing organization's human capital as determinant for OP. According to the RBV theory perspective, the organization's 
human capital is the value gained by developing human resources that are valuable, rare, imperfectly imitable, or without an equivalent substitute, which can be leveraged as a strategic value to improve $\mathrm{OP}$ in Malaysia public sector.

In the past few years, efforts to introduce continuous improvement principles and practices in government have gained increased acceptance as government departments and agencies at the federal, state and local levels evaluate new methods to reduce waste and increase efficiency in improving OP. In this sense, lean management (LM) has been presented as capable to fulfil the needs of key stakeholders, and to stretch their resources towards producing more value for the customers (Li, 2011; Radnor, 2012) since the foundation of LM is to instil in the employees a desire for continuous improvement (Latham, Almost, Mann and Moore, 2005). Several studies have succeeded in providing evidence that LM has a positive impact on performance (Moyano-Fuentes and Sacristán-Díaz, 2012). There is also reliable evidence to show that government can simultaneously improve the quality and lower costs of their activities and make dramatic improvements in efficiency and service by eliminating waste and without spending more money through LM as private sector organizations have done for years (Drotz, 2014).

Michie, Sparrow, Cooper and Hird (2016) note, the application of LM into service sector has further increased the relevance of human resource management (HRM) in a LM context. They find that LM is an opportunity for HRM to review its internal architecture and design to prove more useful in a LM system. Thus, HRM is relevant to LM for mainly three reasons: it aims to bring LM an integration of business strategy with quality, a committed workforce and increased flexibility in terms of organization and job design (Wilkinson, Gamble, Humphrey, Morris and Anthony, 2001), and positive employee attitudes (Zirar, Radnor and Charlwood, 2015).

In recent years, the matter of LM and HRM practices have been commonly used to observe OP especially within private sectors across the globe. One of the distinctive features of LM and HRM practices is that better performance is achieved through the people in the organization. In the literature, the relationship between HRM practices, LM and OP has been well documented by the previous studies. Some studies have noted that LM promotes OP (Shah and Ward, 2003; Li, 2011; Drotz, 2014; Fok-Yew, 2016), other studies argue that it is HRM practices that helps to improve this performance (Huselid, 1995; Becker and Gerhart, 1996; ALDamoe, Yazam and Ahmid, 2012). While, some research suggests that LM and HRM are closely related and can interact in order to improve OP (Bonavia and Marin-Garcia, 2011; Marshall, 2014; Szabo, 2014; Zirar, Radnor, and Charlwood, 2015; Uhrin, Bruque-Cámara and Moyano-Fuentes, 2017). Some of these studies opt for analyzing the moderating effect of HRM practices on the relationship between LM and performance (Ahmad, Schroeder and Sinha, 2003; Uhrin, Bruque-Cámara and Moyano-Fuentes (2017). Another studies opt for analyzing the mediating effect of LM in the relationship between HRM practices and performance (Shah and Ward, 2003; Dal Pont, Furlan and Vinelli, 2008). Surprisingly, lack of study proposes the mediating role of HRM practices in the relationship between LM and OP, which might be expected considering the potential strong interaction between LM and HRM practices. Yet in another fields of studies, there are empirical evidence and theoretical support that underpinning the HRM practices as mediator. For example, Sánchez, Marín and Morales (2015) has proposed the mediating role of HRM practices in the relationship between knowledge management and firm performance, while Koon and Ali (2015) analyze the mediating effect of HRM practices in the relationship between business strategy and employee outcomes.

In addition, limited research has been done in public sector especially in the local authorities (LAs). Although models and frameworks have been developed, a little has been done to assist the LAs in implementing LM to improve their performance. Marshall (2014) in his study states that very few empirical studies of LM investigate the role that human resources play in the overall success of an organization's lean transformation in improving OP. In line with this, Drotz (2014) has found that there is lack of deeper investigations of how lean implementation influence OP and the users in public sectors. Despite these, most of the studies examining the relationship between HRM, LM and OP have been conducted in Western context. It is argued that additional studies are required in different non Western contexts in order to get a broader view of those relationship (Guest, 2011). Therefore, it would be vital to understand whether Western models could be applied in other contexts, particularly in the Asian countries.

This lack of the studies is what underlies the intention behind the present study to offer a different perspective on the role of HRM practices play in the relationship between LM and OP in Malaysia public sector. 
Based on the theoretical reasoning and previous empirical findings, the study then develops a conceptual framework, which investigates from RBV theory perspective, the role of LM in improving OP with the mediating effects of HRM practices in Malaysia LAs. It examines LM from the perspective of RBV which explores the human resources as a key resources that are imperfectly imitable and difficult to duplicate. These key resources are formed by HRM practices of the organization.

This paper begins with a literature review in the area, followed by introducing a conceptual framework and research hypotheses of the study. Finally makes some concluding remarks.

\section{Conceptual Framework}

This study uses the RBV theory to underpin the conceptual framework which explains how organizations use LM and HRM practices as their valuable resources to achieve their goal. It describes human capital as the value gained by developing human resources that are valuable, rare, imperfectly imitable, or without an equivalent substitute. Therefore, human capital can be leveraged as a strategic value to improve organizational outcomes (Cohen, 2011).

The most influential articles about LM related to HRM practices are the studies by Marshall (2014) and most recently research by Uhrin, Bruque-Cámara and Moyano-Fuentes (2017). A RBV is utilized as a theoretical foundation for the framework of the studies. They emphasised the lack of examination of LM related to human dimension in operations management. The researchers' note that many recently published studies referred to the lack of the overall efficiency of the LM practices and made their arguments regarding the use of RBV related to human resources in culture shift. Their respective components of LM and HRM practices of the organization are as observed in Table 1.

Table 1: HRM Practices Related to Lean Management

\begin{tabular}{|c|c|c|}
\hline $\begin{array}{l}\text { Author } \\
\text { (Year) }\end{array}$ & Lean Management & $\begin{array}{c}\text { HRM } \\
\text { Practices }\end{array}$ \\
\hline $\begin{array}{c}\text { Marshall } \\
(2014)\end{array}$ & $\begin{array}{ll}\text { - } & \text { Achievement of } \\
\text { Organizational } \\
\text { Objectives } \\
\text { Improved } \\
\text { Organizational } \\
\text { Capabilities } \\
\text { Alignment with } \\
\text { Business Strategy }\end{array}$ & $\begin{array}{l}\text { - } \\
\text { - } \\
\text { Training and } \\
\text { Development } \\
\text { - } \quad \text { Performance Evaluation } \\
\text { Rewards and Incentives }\end{array}$ \\
\hline $\begin{array}{l}\text { Uhrin, } \\
\text { Bruque- } \\
\text { Cámara } \\
\text { and } \\
\text { Moyano- } \\
\text { Fuentes } \\
(2017)\end{array}$ & $\begin{array}{ll}\bullet & \text { Just -In-Time (JIT) } \\
\text { - } & \text { Cellular Manufacturing } \\
\text { Total Productive } \\
\text { - } & \text { Maintenance (TPM) } \\
& \text { Total Quality } \\
& \text { Management (TQM) }\end{array}$ & $\begin{array}{ll}\text { - } & \text { Active Skill } \\
\text { Development } \\
\text { - } & \text { Highly Skilled } \\
\text { - } & \text { Cross-Functional } \\
\text { Workforce } \\
\text { - } \\
\text { Exchange of Opinions } \\
\text { and Ideas (Feedback) } \\
\text { Problem-Solving } \\
\text { Abilities } \\
\text { Self-Directed Work } \\
\text { Teams }\end{array}$ \\
\hline
\end{tabular}

Marshall (2014) reviewed the study that analysed the impact of HRM practices in the lean transformation success to improve competitive advantage, and view HRM practices as a driver in the relationship between lean transformation success and performance of the organization. Uhrin, BruqueCámara and Moyano-Fuentes (2017) reviewed the study that analysed the role of workforce development in the relationship between lean production and OP, and view workforce development as a moderator in the relationship between LM and OP of the organization. These works reinforce the insight on the role of human resources in LM environments. More specifically, it is assumed that progress in implementing LM with the role play by HRM practices contributes to upgrading the knowledge and skills of employees, and by this means improved performance outcomes can be 
attained. This reaffirms the concept of Shah and Ward (2003) that LM is an integrated socio-technical system oriented to efficiency.

Collectively, the literature indicates that HRM practices will mediate the relationship between LM and OP providing empirical evidence and theoretical support for this study. This study then propose a refined research framework (Fig. 1) resulted from the previous work by Uhrin, Bruque-Cámara \& Moyano-Fuentes (2017), and value-add whenever appropriate to suit the current study. A RBV theory perspective is utilized as a theoretical foundation for the framework. The theory ease understand how HRM practices mediate the relationship between LM and OP. The mediation framework proposes that OP could be improved by implementing LM with the mediating effect of HRM practices in Malaysia public sector. Thus, enhancement in OP is estimated to be explained by LM with the mediating effect of HRM practices. The OP is the dependent variable, the LM is identified as the independent variable, and HRM practices as the mediator variable.

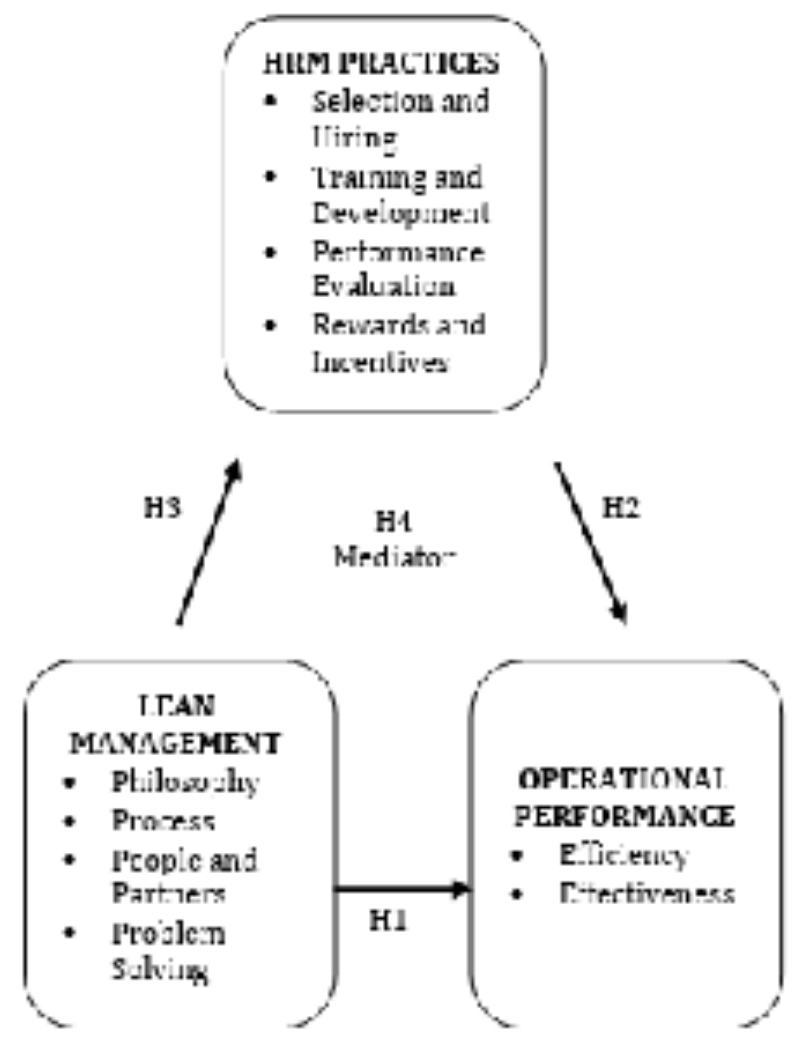

Fig. 1: Conceptual framework

For the independent variable, four dimensions are being identified and they are based on the model developed by Liker (2004) and supported by Dombrowski and Mielke (2013): philosophy, process, people and partners, and problem solving. For HRM practices, four dimensioned are being identified and they are adopted from the work of Marshall (2014): selection and hiring, training and development, performance evaluation, and rewards and incentives. These practices stand as the mediating variables and mediate between the independent and the dependent variables, that is, in the relationship between LM and OP. Following Mouzas (2006) and Hookana (2011), this study measures $\mathrm{OP}$ as an appropriate combination of two dimensions: (1) efficiency, and (2) effectiveness.

\section{Hypotheses Development}

Drawing from RBV theory perspective, the proposed conceptual framework (Fig. 1) integrates three multidimensional constructs (LM, HRM practices and OP). This model comprises two formative second-order constructs (i.e. HRM practices and OP) and four reflective first-order constructs (philosophy, process, people and partners, and problem solving) measured by their respective reflective indicators. The conceptualization of multidimensional constructs and their association with the dimensions underpinning them are derived from theory. The conceptual model proposes that LM has an effects on OP directly and indirectly through the HRM practices. 


\subsection{Relationship between LM and OP}

LM has been marketed as an effective methodology that can dramatically improve the performance of business organizations in the literature (Hu, Wang, Fetch and Bidanda, 2008; Jabbour, de Sousa Jabbour, Govindan, Teixeira and de Souza Freitas, 2013). The primary argument by academics is that implementation of LM will positively affect performance and lead to competitive advantage (Shah and Ward, 2003; Li, 2011; Drotz, 2014; Marshall, 2014).

Scholars argue that implementation of LM improves the competitive position of an organization due to the performance enhancing nature of the LM practices, particularly waste reduction, continuous improvement, and total quality management programs, among others (Sakakibara, Flynn, Schroeder and Morris, 1997; Fullerton and McWatters, 2001).

Based on the aforementioned arguments, this research overall predicts the direct relationship is a positive one, and further hypothesizes that:

H1: LM has a positive and significant relationship with OP of the organization.

\subsection{The Relationship between HRM Practices and OP}

The HRM function within an organization is often described from a systems perspective, where it is designed to accomplish certain objectives, such as motivating performance, developing employees, establishing culture, implementing business strategies, and many others, that ultimately lead to enhanced performance or competitive advantage for the organization (Lado and Wilson, 1994; Becker and Huselid, 1998; Marshall, 2014).

Based on RBV theory perspective, human resource is an intellectual asset, the sum total of the knowledge, skills and competencies that an organization processes and channelizes for sustained organizational excellence. It helps to develop human capabilities and organizational competencies to achieve success.

For the past two decades, researchers have linked HRM practices to manufacturing performance (Jayaram, Droge and Vickery, 1999), OP (Becker and Gerhart, 1996; Ahmad and Schroeder, 2003), organizational effectiveness and performance (Delaney and Huselid, 1996), and competitive advantage (Lado and Wilson, 1994). Also, even though the effects of HRM on performance have not been totally clarified, various studies from different countries produce evidence that the effective management of people results in better performance. For instance, Katou (2008) noted that HRM practices have a direct influence or effect on subordinate attributes such as human skills, attitudes and behavior, the socalled HRM outcomes, which in turn enhances performance.

Study by Ahmad and Schroeder (2003) indicates that HRM practices have a significant impact on employee turnover and performance of firms. Similarly, the research by Bjo“rkman and Xiucheng (2002) found a positive relationship between HRM systems and performance. Accordingly, Pfeffer (1998) observes that human resources have been essential in sustaining OP. Although, it has been generally agreed that HRM is positively associated with OP, however, there is still need for additional research to be undertaken to provide more evidence to support the HRM-performance relationship from different cultural context such as Malaysia and other developing countries.

Resulting from the above arguments, this research overall predicts the direct relationship is a positive one, and put forward the following hypothesis:

H2: HRM practices have positive and significant relationship with OP of the organization.

\subsection{The Relationship between LM and HRM Practices}

A common way to understand LM is through two pillars: continuous improvement and respect for people. In other words, LM is about people and gaining everyone's engagement in continuous improvement. On the other hand, HRM comprises people-related guidelines, policies, programs, philosophy, systems, and practices that organization implement to manage and improve their human resource and bring flexibility to a workplace (Shah and Ward, 2003; Boxall and Purcell, 2011; Armstrong and Tylor, 2014).

The characteristics of LM such as knowledge sharing, continuous improvement concept and senior management support deal with human resources issues and thus have implications on the HRM of lean companies (Beauvallet and Houy, 2009). LM from HRM could be seen from these two viewpoints: (1) LM involves establishing the material conditions and an appropriate HRM that allow a mobilization of employees and management around quality and performance, (2) LM involves integrating middle management and support services with production rather than distance them (Beauvallet and Houy, 2009). 
The HRM practices play a large part in employee motivation and performance. The literature on advanced HRM practices (Huselid, 1995, Pil and MacDuffie, 1996) identifies human resources factors that have a good fit with LM, including teamwork, job rotation, ongoing training, contingent rewards, job security, versatility and participation (Martínez-Jurado, Moyano-Fuentes and Jerez-Gómez, 2014). Ultimately, the goal of the HRM is to provide regular feedback to employees in an effort to enhance continuous improvement and promote achievement of both personal and broader organizational goals (Ferreira and Otley, 2009; Marshall, 2014). Because the human element is a key driver of successful LM transformation, the HRM should reflect the goals and objectives of LM transformation to motivate employee performance, ensure that employees are properly trained, and reward employees equitably for behaving and displaying values that align with the LM transformation strategy (Liker and Hoseus, 2009).

Hence, establishing a LM organizational culture very much depends on the organization's ability to select, develop, engage, and inspire human resources through effective performance management strategies (Marshall, 2014).

Based on the aforementioned reasoning, this research overall predicts the direct relationship is a positive one, and further hypothesises that:

H3: LM has a positive and significant relationship with HRM practices of the organization.

\subsection{The Mediating Effect of HRM Practices on the Relationship between LM and OP}

Many organizations are improving their productivity and competitive advantage through their people (Delery and Doty, 1996), especially when it is considered that people management is an underpinning and essential aspect to the competitiveness of business organization (Sagwa, K'Obonyo and Ogutu, 2015). Human resources are the drivers and principal value creators of the output of the knowledge industry, and also the intellectual capital or the infrastructure investment.

An organization that aspires to perform well should ensure that its HRM practices are synergistic and consistent with its organizational strategy in order to spur both individual and organizational performance (Schuler and Jackson, 1987; Ulrich, 2013, Sagwa, K'Obonyo and Ogutu, 2015). RBV is often use as theory background that describes human capital as the value gained by developing human resources which are valuable, rare, imperfectly imitable, or without an equivalent substitute can lead to sustainable competitive advantage for the organization (Barney, 1991).

In the literature, the relationship between HRM practices, LM and OP has been well documented by the previous studies. The studies suggest that LM and HRM are closely related and can interact in order to improve OP (Bonavia and Marin-Garcia, 2011; Marshall, 2014; Szabo, 2014; Zirar, Radnor and Charlwood, 2015; Uhrin, Bruque-Cámara and Moyano-Fuentes, 2017). Osterman (1994) believed that supporting HRM practices were necessary for successful implementation of flexible work organization. Following the same line, Sakakibara Flynn, Schroeder and Morris (1997) showed a strong relationship between just-in-time (JIT) and what they called infrastructure practices, including workforce management.

In addition, the combination of JIT and infrastructure practices was related to manufacturing performance. Cua, McKone and Schroeder (2001) also showed how LM programs include some HRM practices. Their analysis made clear how the implementation of these human practices, together with total quality management (TQM), JIT, and total productive maintenance (TPM) programs, provides significant explanation for the differences in performance measures (Bonavia and Marin-Garcia, 2011).

Based on the above reasoning, the utilization of the HRM practices is considered to contribute to the positive effects of LM implementation in terms of the OP of the organization. In other words, the HRM practices like selection and hiring, training and development, performance evaluation, and rewards and incentives contributing to workers having the skills and orientations to make LM work in improving OP of the organization. Hence, this research puts forward the following hypothesis:

H4: HRM practices mediate the relationship between LM and OP of the organization.

\section{Conclusions}

Drawing from RBV theory perspective of the organization, in this study, the researcher demonstrates the strategic aspect of both LM and HRM practices, and argued about why these practices can lead to high performance of the organization.

To the researcher knowledge, this study represents the first comprehensive examination of the role that HRM practices play in the overall success of LM transformation in improving OP in Malaysia LAs. This study could build momentum by stimulating new research in public sector that will not only 
close the gaps, but will also lead practice. Hence, it becomes the major contribution to the body of knowledge in the LM public sector operations management literature. This study is anticipated to be a framework for future studies in the academic field and public sector LM implementers.

\section{References}

Ahmad, S., and Schroeder, R.G. (2003). The impact of Human Resource Management Practices on Operational Performance: Recognizing Country and Industry Differences. Journal of Operations Management, 21(1): 19-43.

ALDamoe, F.M.A., Yazam, M., and Ahmid, K.B. (2012). The Mediating Effect of HRM Outcomes (Employee Retention) on the Relationship between HRM Practices and Organizational Performance. International Journal of Human Resource Studies, 2(1): 75.

Armstrong, M., and Taylor, S. (2014). Armstrong's Handbook of Human Resource Management Practice. Kogan Page Publishers.

Barney, J. (1991). Firm Resources and Sustained Competitive Advantage. Journal of Management, 17(1): 99-120.

Beauvallet, G., and Houy, T. (2009). Research on HRM and Lean Management: a Literature Survey. International Journal of Human Resources Development and Management, 10(1): 14-33.

Becker, B., and Gerhart, B. (1996). The Impact of Human Resource Management on Organizational Performance: Progress and Prospects. Academy of Management Journal, 39(4): 779-801.

Becker, B.E., and Huselid, M.A. (1998). High Performance Work Systems and Firm Performance: A Synthesis of Research and Managerial Implications. In Research in Personnel and Human Resource Management.

Björkman, I., and Xiucheng, F. (2002). Human Resource Management and the Performance of Western Firms in China. International Journal of Human Resource Management, 13(6): 853-864.

Black, S.E., and Lynch, L.M. (1996). Human-capital Investments and Productivity. The American Economic Review, 86(2): 263-267.

Bonavia, T., and Marin-Garcia, J.A. (2011). Integrating Human Resource Management into Lean Production and Their Impact on Organizational Performance. International Journal of Manpower, 32(8): 923-938.

Boxall, P., and Purcell, J. (2011). Strategy and Human Resource Management. Palgrave Macmillan.

Challis, D., Samson, D., and Lawson, B. (2005). Impact of Technological, Organizational and Human Resource Investments on Employee and Manufacturing Performance: Australian and New Zealand Evidence. International Journal of Production Research, 43(1): 81-107.

Cohen, J.A. (2011). Intangible Assets: Valuation and Economic Benefit (Vol. 273). John Wiley \& Sons.

Cua, K.O., McKone, K.E., and Schroeder, R.G. (2001). Relationships between Implementation of TQM, JIT, and TPM and Manufacturing Performance. Journal of Operations Management, 19(6): 675-694.

Dal Pont, G., Furlan, A. and Vinelli, A. (2008). Interrelationships among Lean Bundles and Their Effects on Operational Performance. Operations Management Research, 1(2): 150-158.

Dan, W., and Yuxin, E. (2011, January). Impact of Human Resource Management Practices on Operational Performance in Manufacturing Companies. In Management Science and Industrieal Engineering (MSIE), International Conference on IEEE, pp. 56-60.

Delaney, J.T., and Huselid, M.A. (1996). The impact of Human Resource Management Practices on Perceptions of Organizational Performance. Academy of Management Journal, 39(4): 949-969.

Delery, J.E., and Doty, D.H. (1996). Modes of Theorizing in Strategic Human Resource Management: Tests of Universalistic, Contingency, and Configurational Performance Predictions. Academy of Management Journal, 39(4): 802-835. 
Dombrowski, U., and Mielke, T. (2013). Lean Leadership-Fundamental Principles and Their Application. Procedia CIRP, 7, pp. 569-574.

Drotz, E. (2014). Lean in the Public Sector: Possibilities and Limitations. PhD Dissertation, Linköping University Electronic Press.

EPU (Economic Planning Unit). (2017). Economic Planning Unit. Putrajaya.

Ferreira, A., and Otley, D. (2009). The Design and Use of Performance Management Systems: An Extended Framework for Analysis. Management Accounting Research, 20(4): 263-282.

Fok-Yew, O. (2016). The Mediating Role of Lean Engagement on Lean Practices and Business Excellence in Malaysia Electrical and Electronics Companies. International Journal of Academic Research in Economics and Management Sciences. 5(2): 35-45.

Fullerton, R.R., and McWatters, C.S. (2001). The Production Performance Benefits from JIT Implementation. Journal of Operations Management, 19(1): 81-96.

Guest, D.E. (2011). Human Resource Management and Performance: Still Searching for Some Answers. Human Resource Management Journal, 21(1): 3-13.

Hamid, S.M.B.A., Hamali, J.B.H., and Abdullah, F. (2016). Performance Measurement for Local Authorities in Sarawak. Procedia-Social and Behavioral Sciences, 224, pp. 437-444.

Hatch, N.W., and Dyer, J.H. (2004). Human Capital and Learning as a Source of Sustainable Competitive Advantage. Strategic Management Journal, 25(12): 1155-1178.

Hookana, H. (2011). Measurement of Effectiveness, Efficiency and Quality in Public Sector Services: Interventionist Empirical Investigations. In MIC 2011: Managing Sustainability? Proceedings of the 12th International Conference, Portorož, 23-26 November 2011 [Selected Papers] (pp. 491-510). University of Primorska, Faculty of Management Koper.

Hu, G., Wang, L., Fetch, S., and Bidanda, B. (2008). A Multi-Objective Model for Project Portfolio Selection to Implement Lean and Six Sigma Concepts. International Journal of Production Research, 46(23): 6611-6625.

Huselid, M.A. (1995). The Impact of Human Resource Management Practices on Turnover, Productivity, and Corporate Financial Performance. Academy of Management Journal. 38(3): 635-672.

Jabbour, C.J.C., de Sousa Jabbour, A.B.L., Govindan, K., Teixeira, A.A., and de Souza Freitas, W.R. (2013). Environmental Management and Operational Performance in Automotive Companies in Brazil: The Role of Human Resource Management and Lean Manufacturing. Journal of Cleaner Production. 47: 129-140.

Jayaram, J., Droge, C., and Vickery, S.K. (1999). The Impact of Human Resource Management Practices on Manufacturing Performance. Journal of Operations Management, 18(1): 1-20.

Katou, A.A. (2008). Measuring the Impact of HRM on Organizational Performance. Journal of Industrial Engineering and Management, 1(2): 119-142.

Koon, V. Y., \& Ali, J. (2015). The Mediating Effect of HRM Practices on the Relationship between Business Strategy and Employee Outcomes. In Paper Presented at the AeU-International Research Conference, October 4, 2015, Asia e University (pp. 1-14). Asia e University.

Lado, A.A., and Wilson, M.C. (1994). Human Resource Systems and Sustained Competitive Advantage: A Competency-Based Perspective. Academy of Management Review, 19(4): 699-727.

Latham, G.P., Almost, J., Mann, S., and Moore, C. (2005). New Developments in Performance Management. Organizational Dynamics, 34(1): 77-87.

Li, C. (2011). A Customised Lean Model for a Chinese Aerospace OEM (Original Equipment Manufacturer). MSc Thesis, Cranfield University.

Liker, J. (2004). The Toyota Way: 14 Management Principles from the World's Greatest Manufacturer. New York: McGraw-Hill. 
Liker, J.K., and Hoseus, M. (2009). Human Resource Development in Toyota Culture. International Journal of Human Resources Development and Management, 10(1): 34-50.

Marshall, D.A. (2014). Lean Transformation: Overcoming the Challenges, Managing Performance, and Sustaining Success. PhD Dissertation, University of Kentucky.

Martinez-Jurado, P.J., Moyano-Fuentes, J., and Jerez-Gómez, P. (2014). Human Resource Management in Lean Production Adoption and Implementation Processes: Success Factors th the Aeronautics Industry. BRQ Business Research Quarterly, 17(1): 47-68.

Michie, J., Sparrow, P., Cooper, C., and Hird, M. (2016). Do We Need HR?: Repositioning People Management for Success. Springer.

Mouzas, S. (2006). Efficiency versus Effectiveness in Business Networks. Journal of Business Research, 59(10): 1124-1132.

Moyano-Fuentes, J., and Sacristán-Díaz, M. (2012). Learning on Lean: a Review of Thinking and Research. International Journal of Operations \& Production Management, 32(5): 551-582.

MPC (Malaysia Productivity Corporation). (2017). Productivity Report 2016/2017. Malaysia Productivity Corporation. Petaling Jaya.

Myers, M.B., Griffith, D.A., Daugherty, P.J., and Lusch, R.F. (2004). Maximizing the Human Capital Equation in Logistics: Education, Experience, and Skills. Journal of Business Logistics, 25(1): 211-232.

Osterman, P. (1994). How Common is Workplace Transformation and Who Adopts It?. ILR Review, 47(2): 173-188.

Pfeffer, J. (1998). Seven Practices of Successful Organizations. California Management Review, 40(2): 96-124.

Pil, F.K., and MacDuffie, J.P. (1996). The Adoption of High-Involvement Work Practices. Industrial Relations: A Journal of Economy and Society, 35(3): 423-455.

Radnor, Z. (2012). Why Lean Matters: Understanding and Implementing Lean in Public Services. New York: Advanced Institute of Management Research (AIM).

Sagwa, E.V., K'Obonyo, P., and Ogutu, M. (2015). Mediation Effect of Employee Outcomes in the Relationship between Human Resource Management Practices and Performance of Firms Listed on the Nairobi Securities Exchange.

Sakakibara, S., Flynn, B.B., Schroeder, R.G., and Morris, W.T. (1997). The Impact of Just-In-Time Manufacturing and Its Infrastructure on Manufacturing Performance. Management Science, 43(9): 1246-1257.

Sánchez, A. A., Marin, G. S., \& Morales, A. M. (2015). The Mediating Effect of Strategic Human Resource Practices on Knowledge Management and Firm Performance. Revista Europea de Dirección y Economía de la Empresa, 24(3): 138-148.

Schuler, R.S., and Jackson, S.E. (1987). Linking Competitive Strategies with Human Resource Management Practices. The Academy of Management Executive (1987-1989), pp. 207-219.

Shah, R., and Ward, P.T. (2003) Lean Manufacturing: Context, Practice Bundles, and Performance. Journal of Operations Management, 21(2): 129-149.

Szabo, T.D. (2014). Strategic Human Resource Management and Lean Transformation in Sunrise Health Region. Master Thesis, Athabasca University, Canada.

Uhrin, A., Bruque-Cámara, S., and Moyano-Fuentes, J. (2017). Lean Production, Workforce Development and Operational Performance. Management Decision, 55(1).

Ulrich, D. (2013). Human Resource Champions: The Next Agenda for Adding Value and Delivering Results. Harvard Business Press.

Wilkinson, B., Gamble, J., Humphrey, J., Morris, J., and Anthony, D. (2001). The New International Division of Labour in Asian Electronics: Work Organization and Human Resources in Japan and Malaysia. Journal of Management Studies, 38(5): 675-695. 
Wright, P.M. and McMahan, G.C. (1992). Theoretical Perspectives for Strategic Human Resource Management. Journal of Management, 18(2): 295-320.

Wright, P.M., McMahan, G.C. and McWilliams, A. (1994). Human Resources and Sustained Competitive Advantage: A Resource-Based Perspective. International Journal of Human Resource Management, 5(2): 301-326.

Zirar, A.A., Radnor, Z.J., and Charlwood, A. (2015). The Relevance of the Human Resource Management (HRM) To Lean in the Service Sector: Evidence from Three Exploratory Case Studies. 